\title{
Paced Tapping Test Functional Test
}

National Cancer Institute

\section{Source}

National Cancer Institute. Paced Tapping Test Functional Test. NCI Thesaurus. Code C150911.

A cognitive test that is used to assess sensorimotor synchronization and timing of movement, where a subject produces a series of finger taps, at first in time with an external pacing stimulus and then continuing after the stimulus has ended. 